\title{
Elos darwinianos na literatura vitoriana e modernista
}

Nelson Aprobato Filho ${ }^{I}$

O final do século XIX, ou mais precisamente em 1895, leitores britânicos e norte-americanos entraram em contato com um registro literário que provavelmente causou, pelo menos para alguns, um certo mal-estar e uma espécie indelével de estranhamento. ${ }^{1}$ Talvez tenha sido esse mesmo o objetivo do escritor ao publicar o trabalho. Em determinado trecho da obra, com certeza um dos mais polêmicos, ele escreveu:

In writing of man, I feel that I have not entirely lost my old nature, - I am not altogether a human beast in intellect. For if I have lost the past happy sense of unity with nature, I have never lost the present idea of its possibility. And it is individuality, the sense of separation in being from nature, which marks man as a distinct animal from all others.

I think, too, if I had been wholly man, I could never have felt so strongly as I do the fact that intellect is lower than instinct.

I say intellect is a cursed gift - a gift flowing from evil, destroying natural instinctive happiness, and introducing unnatural misery and unnatural immorality.

Esse fragmento é parte da primeira novela escrita por Frank Challice Constable e publicada em 1895, anonimamente, em Endimburgo, Reino Unido; e com o pseudônimo de Machiavelli Colin Clout na cidade de Boston, Estados Unidos. Trata-se da história de um chimpanzé, introduzido na sociedade londrina por
Reuben Power, um pós-darwinista ateu que domesticou e educou o animal com o objetivo de pesquisar se as emoções ou a capacidade intelectual formam a base da felicidade humana. O autor da passagem transcrita aqui é o treinado chimpanzé que, atendendo a um conselho de Power, resolveu escrever suas observações sobre o homem. Power e o chimpanzé são os principais protagonistas da narrativa intitulada The curse of intellect (Constable, 1895, p.132-3).

Frank Challice Constable fez parte de uma corrente literária que teve início em 1859 e que dialogou, de diversas maneiras, com vários aspectos da Teoria da Evolução de Charles Darwin. Além dele, renomados escritores como Franz Kafka, Rudyard Kipling, Arthur Conan Doyle, Robert Louis Stevenson, H. G. Wells, entre outros, também fizeram suas incursões pelo até então quase desconhecido mundo darwiniano. Explorar essas complexas camadas de intertextualidades e interdisciplinaridades pode, com certeza, trazer novos esclarecimentos não só para os estudos literários, mas também para outras áreas do conhecimento humano. É isso o que fez Virginia Richter em seu livro Literature after Darwin. Human Beasts in Western Fiction, 1859-1939, publicado na GrãBretanha em 2011. ${ }^{2}$

Professora, pesquisadora e chefe do departamento de Modern English Literature, da Universität Bern, na Suíça, durante dez anos Richter investigou em profundidade as relações entre literatu- 
ra e ciência ou, mais especificamente, as múltiplas conexões entre determinada produção literária ficcional e a Teoria da Evolução.

O que é ser humano? Quais são os elementos que nos tornam humanos? Por que nos relacionamos de forma tão intensa e tão tensa com outras espécies de animais? Quais são as singularidades do homem? Quais são os limites entre ser humano e ser animal? O homem é realmente uma espécie única e diferenciada das demais? O homem é simplesmente o resultado de um longo, complexo e difuso processo evolucionário? Seria possível encontrar, um dia, todos os "elos perdidos" da evolução do homem? A espécie humana tende à perfeição ou se aproxima, em muitas ocasiões, da degeneração, da desumanização e da bestialização? Questões como essas acompanham todo o desenvolver do livro e adquirem ainda mais consistência e relevância histórica e interpretativa se for levada em consideração a periodização adotada por Richter. Os registros ficcionais incluídos por ela no livro foram produzidos no período compreendido entre a publicação de $O n$ the origen of species, 1859, e o início da Segunda Guerra Mundial, 1939. Trata-se de um momento crucial para a história não só da humanidade, mas de todas as formas de vida existentes no planeta. Da Teoria da Evolução à Revolução Científico-Tecnológica; da Primeira à Segunda Guerra Mundial; do imperialismo britânico à ascensão do nazismo etc., entre 1859 e 1939 o homem criou e conheceu realidades nunca antes experimentadas. Literature after Darwin pode contribuir para pensar essas realidades; para pensar sobre o homem e essas suas tão marcantes singularidades.

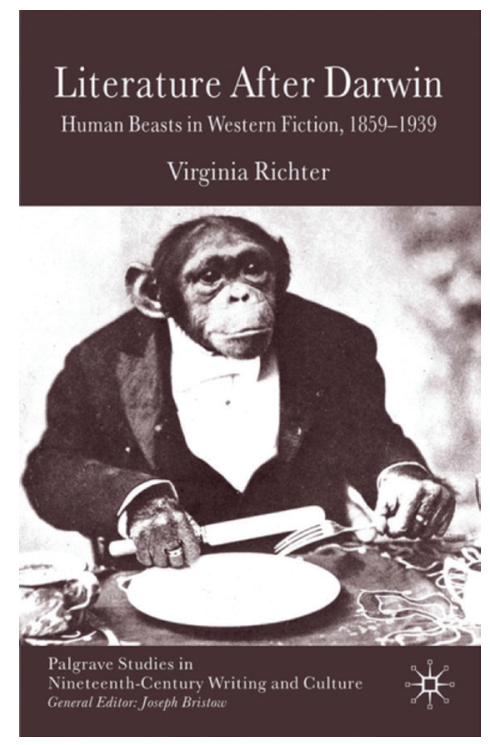

RICHTER, V. Literature after Darwin.

Human Beasts in Western Fiction, 1859-1939. Hampshire, Great Britain: Palgrave Macmillan, 2011.

Dos autores do final da era vitoriana aos escritores modernistas, a autora fez uma criteriosa seleção que, de diversas maneiras, dialoga com as questões enunciadas no parágrafo acima. Alguns dos textos elencados por Richter são de rara profundidade, como "Report for an Academy", de Franz Kafka, ou "Bertran and Bimi" e "The Mark of the Beast", de Rudyard Kipling. Outros são de incontestável popularidade, como King Solomon's Mines, de Henry Rider Haggard; Tarzan of the Apes e The return of Tarzan, de Edgar Rice Burroughs; The lost world, de Arthur Conan Doyle; Strange case of Dr Jekyll and Mr Hyde, de Robert Louis Stevenson; The island of $\mathrm{Dr}$ Moreau e The time machine, de H. G. Wells. Por fim, os demais registros literários selecionados pela autora são hoje em dia bem menos conhecidos do público em geral, como o citado 
The curse of intellect, de Frank Challice Constable; His Monkey wife or, married to a Chimp, de John Collier; Captured by cannibals, de Joseph Hatton; A queer race: the story of a strange people, de William Westall; Greem Mansions, de William Henry Hudson; The story of $A b$. A tale of the time of the Cave Man, de Stanley Waterloo; The coming race, de Edward Bulwer-Lytton; The war with the Newts, de Karel Čapek.

O trabalho de Richter é teórica e metodologicamente bem construído. A autora transita com muita facilidade entre literatura, ciência e filosofia. Nos dois primeiros capítulos do livro "What animal? Darwin's displacement of Man" e "Creating connections: humans, apes and missing links", espécie de uma introdução ao tema, Richter, além de justificar e descrever os objetivos principais do livro, apresenta uma síntese crítica e bem elaborada da Teoria da Evolução e das discussões surgidas após a divulgação das ideias de Darwin. Por meio dessa longa síntese introdutória pode-se perceber a grande desenvoltura intelectual que a pesquisadora tem com áreas aparentemente distantes de seu campo principal de investigação que é a crítica literária. Entre outras especializações, Richter vem trabalhando, há bastante tempo, com as intrincadas relações entre literatura, ciência e darwinismo; com as representações literárias de animais; e com as conexões entre literatura e meio ambiente. Essas habilidades, que podem ser percebidas no livro, resultaram na construção de uma narrativa elegante, envolvente, desafiadora, equilibrada e com um conteúdo até certo ponto inédito.

Tão importante quanto o estilo e o conteúdo apresentados na obra é a pos- tura teórica e metodológica adotada por Richter. Ao apostar na interdisciplinaridade a autora sem dúvida contribui com um passo importante e inequívoco para as investigações no campo das humanidades e aproxima-se, de certa forma, de outros importantes pesquisadores.

No campo da história, por exemplo, o pesquisador norte-americano John Lewis Gaddis teceu algumas considerações bastante sugestivas sobre o tema em seu livro Paisagens da história (Gaddis, 2003). Logo no início da obra o renomado professor da Yale University lembrava que Marc Bloch e Edward Hallett Carr já haviam previsto, em meados do século XX, "alguns desenvolvimentos nas ciências físicas e biológicas que aproximaram essas disciplinas do trabalho realizado ao longo do tempo pelos historiadores". Em outras palavras, segundo Gaddis (2003, p.11), eles acreditavam na "convergência do método histórico com aqueles das ciências chamadas exatas". Além de demonstrar, de forma muito clara, várias dimensões dessa convergência - tratando de temas que vão da Teoria da Evolução à Teoria do Caos e da Complexidade -, o pesquisador argumentava, de maneira inovadora e incitante, que o trabalho do historiador está muito mais próximo daqueles desenvolvidos pelos cientistas naturais do que necessariamente de áreas aparentemente mais imediatas. "As comparações", sugere Gaddis,

[...] poderiam esclarecer as formas de interação com outras disciplinas. As similaridades temáticas não necessariamente implicam similaridades metodológicas, uma questão que Bloch e Carr tentaram formular ao enfatizar a compatibilidade entre os métodos dos historiadores e dos 
cientistas naturais. O problema é que as ciências sociais, nas quais os modelos estáticos são ainda valorizados e a evolução é quase sempre vista como um incômodo confuso, podem não ser um campo ideal para os historiadores buscarem as analogias que os ajudariam em suas definições. (ibidem, p.68)

E foi justamente a questão da evolução que Richter abordou em sua obra. $\mathrm{O}$ objetivo principal da autora não foi simplesmente refletir sobre o impacto da Teoria da Evolução na produção literária por ela analisada. Além de fazer isso com bastante propriedade, a autora procurou principalmente detectar e discutir, a partir desses registros literários, algumas das principais questões científicas, éticas e religiosas que surgiram a partir de 1859, ano da publicação de $O n$ the origen of species. Pode-se afirmar que Richter se propôs a refletir sobre a intertextualidade praticada por esses escritores ao incorporarem em suas produções ficcionais as "grandes ansiedades" que começaram a atormentar as mentalidades, principalmente ocidentais, após as proposições darwinianas.

Para a autora foram duas as "grandes ansiedades" que causaram angústia e inquietação nos meios científicos, acadêmicos e religiosos, criando acirradas discussões intelectuais e perpassando, de forma contundente e singular, os escritores e os livros eleitos por ela. Em primeiro lugar, ela começa suas análises literárias com um estudo aprofundado da "Anxiety of simianation" (capítulo 3 do livro) em narrativas nas quais os macacos, enquanto personagens, têm destaque especial, estão em frequente e definitivo contato com o homem e representam a precariedade da autodefinição humana. Nesse capítulo Richter reflete sobre as discussões em torno da questão da identidade e da alteridade surgidas a partir das ideias evolutivas que relacionaram o homem aos grandes primatas. Em seguida a pesquisadora trabalha com a ideia da "The anxiety of assimilation" (capítulo 4) na ficção imperial. Tendo como contexto histórico o imperialismo britânico do século XIX, os autores estudados por ela fixaram suas narrativas na "zona de contato colonial" e abordaram questões como o medo de assimilação e regressão do homem europeu para com os povos coloniais. $\mathrm{O}$ que estava em jogo era a busca dos inatingíveis missing links, ou seja, a grande ansiedade por encontrar e reconstruir os "elos perdidos" do longínquo passado da espécie humana, o que significaria uma das formas para comprovação e compreensão da evolução do homem. O selvagem representava, assim, esse "elo perdido".

No capítulo 5 do livro Richter aborda a questão das ansiedades em torno das relações entre degeneração cultural e pessimismo cultural, primeiramente no contexto do grande empreendimento imperialista do final do século XIX e, em seguida, após a Primeira Guerra Mundial. A "Anthropological anxiety" presente nos autores analisados por ela reflete ideias em voga no período que procuravam classificar e separar as supostas "raças" e culturas superiores das supostas "raças" e culturas inferiores.

Apenas duas ressalvas poderiam ser feitas ao livro, mesmo levando em consideração não terem sido elas parte dos objetivos da autora. Os estudiosos da literatura talvez fiquem interessados em saber mais profundamente qual foi a recepção que os livros analisados pela pesquisadora receberam no período em 
que foram publicados. Os historiadores, por seu lado, talvez considerem que $\mathrm{Ri}$ chter enriqueceria suas interpretações se tivesse entabulado um diálogo mais consistente entre os registros literários e documentos históricos de outra natureza. Mas nem por isso o livro perde em qualidade e ineditismo.

A leitura de Literatura after Darwin pode ser proveitosa para especialistas de várias áreas e leigos de díspares interesses. Pode ser fonte de inspiração e reflexão para pensarmos especificidades da história, da literatura, da ciência e da religião que se desenvolveu no Brasil. A partir de 1859 não só os leitores brasileiros entraram em contato com muitos dos textos e escritores analisados por Richter, como dialogaram, a partir de várias matrizes e áreas do conhecimento, com as proposições enunciadas por Darwin.

Literatura after Darwin pode ser lido, enfim, como uma profunda e provocativa reflexão sobre o lugar, o papel e o futuro do homem no planeta. No livro podem ser encontrados consistentes elementos para pensar como esse lugar, esse papel e esse futuro vêm sendo construídos, discutidos e projetados seja pela literatura ou pela crítica literária, seja pela história ou pela religião, seja pela ciência ou pela tecnologia. Ao pensar sobre o homem e os outros animais, todos estamos incluídos na obra de Richter. O principal desafio lançado subliminarmente pela autora é o de como sabermos ao certo qual é o lugar que ocupamos e qual é o papel que representamos no mundo pós-Darwin e, ao fim e ao cabo, o que podemos fazer para tornar esse mundo melhor.

\section{Notas}

l O conceito de estranhamento utilizado aqui é aquele desenvolvido por Carlo Ginzburg no estudo "Tolerância e comércio - Auerbach lê Voltaire”. Para Ginzburg, o estranhamento é um "processo literário que transforma uma coisa familiar - um objeto, um comportamento, uma instituição - numa coisa estranha, insensata, ridícula". Pensando especificamente na relação entre estranhamento e o universo dos animais, em outro ensaio - "Os europeus descobrem (ou redescobrem) os xamãs" -, Ginzburg lembra que no "rastro dos formalistas russos, sendo o primeiro de todos Chklóvski, aprendemos a procurar o estranhamento no olhar do selvagem, da criança, ou até mesmo do animal: seres estranhos às convenções do viver civilizado, que registram com olhar perplexo ou indiferente, denunciando assim, indiretamente, a insensatez das coisas" (cf. Ginzburg, 2007, p.112-38 e p.95).

$2 \mathrm{O}$ trabalho foi originalmente apresentado como relatório de pós-doutorado e como um dos requisitos para Richter ingressar como Professor na Universidade de $\mathrm{Mu}^{-}$ nique.

\section{Referências}

CONSTABLE, F. C. The curse of intellect. Edinburg: William Blackwood \& Sons, 1895.

GADDIS, J. L. Paisagens da história. Como os historiadores mapeiam o passado. Trad. Marisa Rocha Motta. Rio de Janeiro: Campus, 2003.

GINZBURG, C. O fio e os rastros: verdadeiro, falso, fictício. Trad. Rosa Freire d'Aguiar e Eduardo Brandão. São Paulo: Cia. das Letras, 2007.

Tolerância e comércio: Auerbach lê Voltaire. In: _. O fio e os rastros: verdadeiro, falso, fictício. Tradução Rosa Freire d'Aguiar e Eduardo Brandão. São Paulo: Cia. das Letras, 2007. 
GINZBURG, C. Os europeus descobrem (ou redescobrem) os xamãs. In: O fio e os rastros: verdadeiro, falso, fictício. Tradução Rosa Freire d'Aguiar e Eduardo Brandão. São Paulo: Cia. das Letras, 2007.

RICHTER, V. Literature after Darwin. Human Beasts in Western Fiction, 18591939. Hampshire, Great Britain: Palgrave Macmillan, 2011.

Nelson Aprobato Filho é doutor em História Social pela Faculdade de Filosofia, Letras e Ciências Humanas da Universidade de São Paulo; Visiting scholar no Massachusetts Institute of Technology (MIT). Pós-doutorando em História na FFLCHUSP. Bolsista Fapesp. Autor, entre outras publicações, do livro Kaleidosfone - As novas camadas sonoras da cidade de São Paulo, fins do século XIX / início do XX (Edusp/Fapesp, 2008).

@ - aprobato@usp.br

${ }^{\text {I }}$ Faculdade de Filosofia, Letras e Ciências Humanas, Universidade de São Paulo, São Paulo/SP, Brasil. 